\title{
Explaining the eventual transient saturation of climate-carbon cycle feedback
}

\author{
Igor I Mokhov and Alexey V Eliseev*
}

Address: A.M. Obukhov Institute of Atmospheric Physics RAS, Moscow, Russia

Email: Igor I Mokhov - mokhov@ifaran.ru; Alexey V Eliseev* - eliseev@ifaran.ru

* Corresponding author

Published: 28 April 2008

Carbon Balance and Management 2008, 3:4 doi:10.1186/1750-0680-3-4

This article is available from: http://www.cbmjournal.com/content/3///4

(C) 2008 Mokhov and Eliseev; licensee BioMed Central Ltd.

This is an Open Access article distributed under the terms of the Creative Commons Attribution License (http://creativecommons.org/licenses/by/2.0), which permits unrestricted use, distribution, and reproduction in any medium, provided the original work is properly cited.
Received: 19 December 2007

Accepted: 28 April 2008

\begin{abstract}
Background: Coupled climate-carbon cycle simulations generally show that climate feedbacks amplify the buildup of $\mathrm{CO}_{2}$ under respective anthropogenic emission. The effect of climate-carbon cycle feedback is characterised by the feedback gain: the relative increase in $\mathrm{CO}_{2}$ increment as compared to uncoupled simulations. According to the results of the recent Coupled ClimateCarbon Cycle Model Intercomparison Project ( $\left.{ }^{4} M I P\right)$, the gain is expected to increase during the 2 Ist century. This conclusion is not supported by the climate model developed at the A.M. Obukhov Institute of Atmospheric Physics at the Russian Academy of Sciences (IAP RAS CM). The latter model shows an eventual transient saturation of the feedback gain. This saturation is manifested in a change of climate-carbon cycle feedback gain which grows initially, attains a maximum, and then decreases, eventually tending to unity.
\end{abstract}

Results: Numerical experiments with the IAP RAS CM as well as an analysis of the conceptual framework demonstrate that this eventual transient saturation results from the fact that transient climate sensitivity decreases with time.

Conclusion: One may conclude that the eventual transient saturation of the climate-carbon cycle feedback is a fundamental property of the coupled climate-carbon system that manifests itself on a relevant time scale.

\section{Background}

Starting from the works $[1,2]$, climate-carbon cycle interactions in the global numerical models attain a lot of scientific attention. These and subsequent works [3-12] have found that an interactive coupling between climate and carbon cycle enhances the build up of the carbon dioxide in the atmosphere, $C$, in comparison to the hypothetical case when the carbon cycle does not respond to the climate changes. If the changes of the atmospheric carbon dioxide in these two cases are $\Delta q_{\mathrm{CO}_{2}}^{c p l}$ and $\Delta q_{\mathrm{CO}_{2}}^{u c p l}$, respec- tively, then the parameter of the climate-carbon cycle feedback is

$$
f=\Delta q_{\mathrm{CO}_{2}}^{c p l} / \Delta q_{\mathrm{CO}_{2}}^{u c p l} .
$$

In [5], the following expression for climate-carbon cycle feedback gain $g=(f-1) / f$ is derived

$$
g=-\alpha\left(\gamma_{l}+\gamma_{o c}\right) /\left(c_{0}+\beta_{l}+\beta_{o c}\right)=-\alpha \mathrm{G}
$$


with transient temperature sensitivity $\alpha=d T_{g}^{c p l} / d q_{\mathrm{CO}_{2} c p l}, T_{g}^{c p l}$ is globally and annually averaged surface air temperature in the coupled simulation, and $c_{0}$ $=2.1 \mathrm{PgC} / p p m v$. Coefficients $\beta_{X}$ and $\gamma_{X}$ come from linear decomposition of respective differential (i.e., per year) terrestrial and oceanic differential carbon uptakes $(X=l$ or $X$ $=O c$ respectively):

$$
F_{X}=\beta_{X} \frac{d q \mathrm{CO}_{2}}{d t}+\gamma_{X} \frac{d T_{g}}{d t}
$$

where $t$ stands for time.

For temporal variations of the parameter $f$ in the course of a given emission scenario, [13] demonstrated a monotonic increase of $f$ during the long-term integration of the Lawrence Livermore National Laboratory coupled model. In the framework of the Coupled Climate-Carbon Cycle Model Intercomparison Project ( $\left.\mathrm{C}^{4} \mathrm{MIP}\right)[14]$, time variations of the respective gains $g$ have been studied for the 21 st sentury (their Fig. 2b). In the latter case, a tendency for increase of this gain during the course of integration forced by the emission scenario SRES A2 has been exhibited as well. However, according to Fig. 2b in [14], one model exhibits decrease of $g$ in the late 21 st century and a few others show a slower decrease in the second part of this century in comparison to the first part.

In turn, a non-monotonic change of $f$ in the simulation with the IAP RAS climate model of intermediate complexity (IAP RAS CM) under the same scenario SRES A2 was obtained $[11,15]$. In this simulation, parameter $f$ grows during the most part of the run but starts to decrease late in the 21 st century. Futher, based on a conceptual climatecarbon cycle model, it has been demonstarted that plausible physical reason for this eventual transient saturation is a weak, logarithmic dependence of the $\mathrm{CO}_{2}$ radiative forcing on the atmospheric concentration of carbon dioxide [16]. This leads to small influence of an additional (due to climate-carbon cycle interactions) build up of the carbon dioxide on climate state when $C$ is large. Given a length of integration, the latter condition is fulfilled only if emissions are aggressive enough.

However, the build up of the carbon dioxide in the atmosphere in the uncoupled simulation was prescribed in [16] and it is unclear how to relate directly time scales associated with this build up with time scales associated with changes in $\mathrm{CO}_{2}$ emissions. In the present paper, ensemble simulations with an Earth system model IAP RAS CM [10$12,15,17$ ] forced by idealised emission scenarios are performed. In this, it is demonstrated that an eventual transient climate-carbon cycle saturation may be exhibited

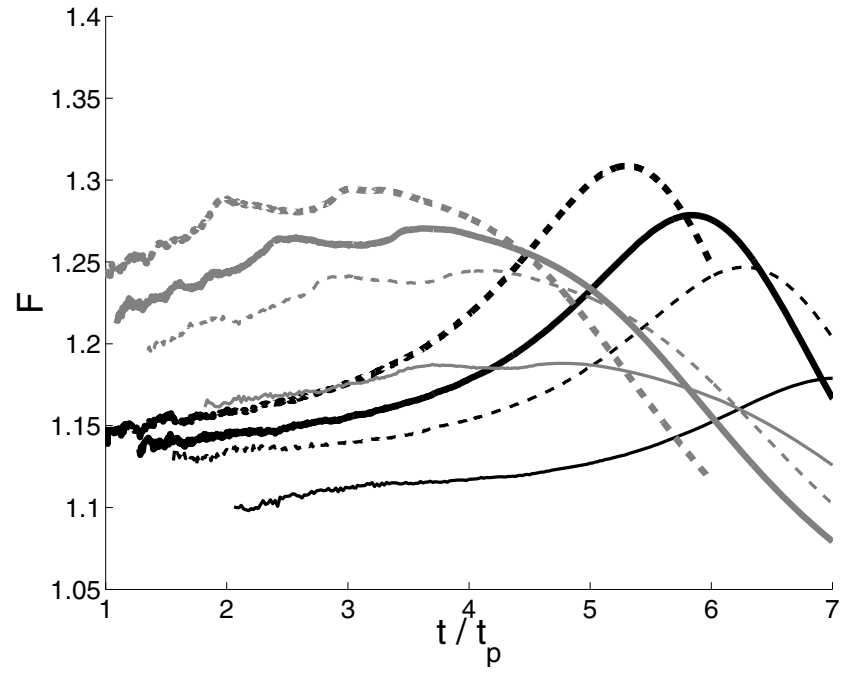

Figure I

Parameter of climate-carbon cycle interaction as a function of $t / t_{p}$, obtained in simulations with the IAP RAS CM versions FocL and FocNL (gray and black curves correspondingly) for $t_{p}=50 \mathrm{yr}$ (thin solid lines), $t_{p}=100 \mathrm{yr}$ (thin dashed lines), $t_{p}=150 \mathrm{yr}$ (thick solid lines), and $t_{p}=\mathbf{2 5 0} y r$ (thick dashed lines). In this and subsequent Figures, the data beyond $t=7 \times t_{p}$ are not shown because they either out of the simulation length or start to show signs of numerical instability. In addition, data with $\Delta q_{\mathrm{CO}_{2}}^{u c p l, c p l}<5$ ppmv are eliminated from plots.

also under moderate emission scenarios if respective integration proceeds for a sufficient time. The results obtained in [16] are supported and it is shown that the above-mentioned hypothesis is proved and even weak but continuing emissions lead to eventual saturation of the climatecarbon cycle feedback. In addition, the IAP RAS CM simulations are supported by integrations with a conceptual coupled model. The latter model is similar, but not identical to that used in [16]. In particular, in the model used here, emissions of $\mathrm{CO}_{2}$ are used instead of prescribing the atmospheric carbon dioxide build up in the uncoupled simulation. It is also demonstrated that eventual transient saturation of climate-carbon cycle feedback in the IAP RAS $\mathrm{CM}$ is consistent with that derived from the earlier version of conceptual model.

\section{Results and Discussion}

\section{Analysis of a numerical coupled model}

A series of numerical experiments with two IAP RAS CM versions were performed. In one version, oceanic uptake of anthropogenic carbon is formulated as a bilinear function of time derivatives of atmospheric concentration of 


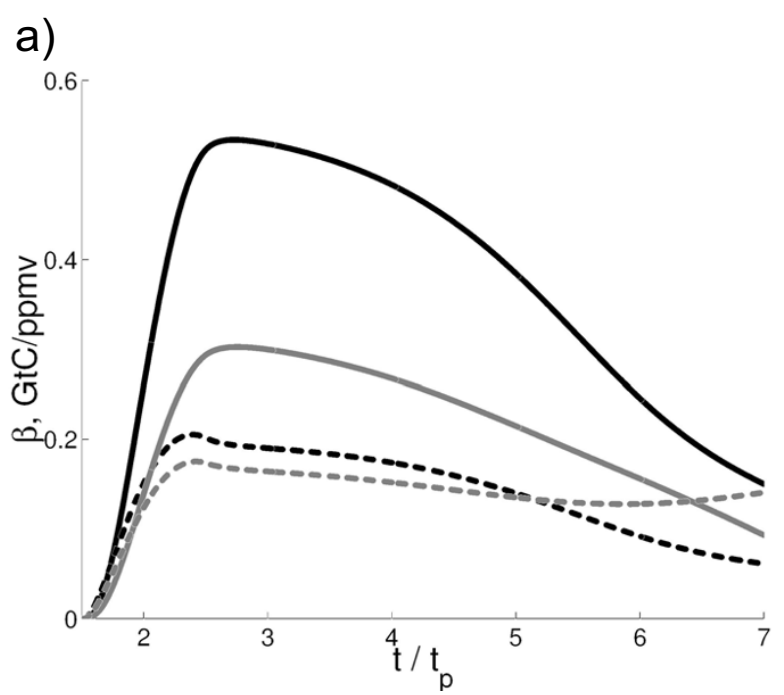

b)

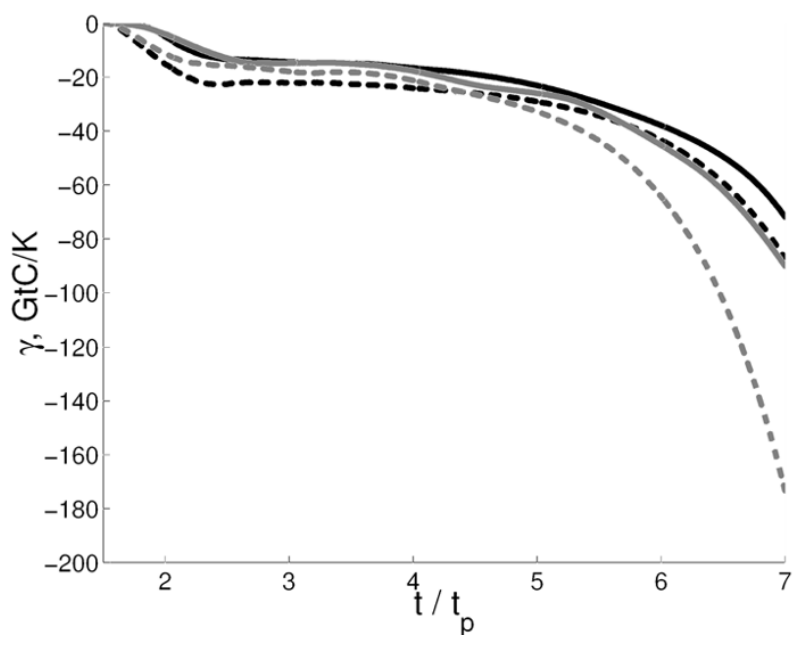

Figure 2

a) Coefficients $\beta_{1}$ and $\beta_{\text {oc }}$ (solid and dashed curves respectively) computed for 100 -year running segments from the simulations with the IAP RAS CM versions FocL and FocNL (gray and black lines correspondingly) as a function of $t / t_{p}$. b) Similar to a) but for coefficients $\gamma_{1}$ and $\gamma_{o c}$.

$\mathrm{CO}_{2}$ and globally averaged annual mean sea surface temperature. Hereafter, this version is denoted as FocL. In other version, oceanic uptake of carbon $F_{o c}$ is determined employing a nonlinear model [18] but with chemical constants computed as functions of temperature in accordance to [19]. In particular, this version takes into account carbonate dissolution in the ocean. Hereafter, this version is denoted as FocNL. Terrestrial uptakes for both model versions are determined based on a zero-dimensional module taking into account direct plants fertilisation by $\mathrm{CO}_{2}$ and influence of climate (expressed via temperature anomaly from the model's preindustrial state employing $Q_{10}$-relationships) on biospheric productivity and autotrophic and heterotrophic respiration. Half-saturation point for the direct plant fertilisation was set to 150 $p p m v$ in the version FocL and to $460 p p m v$ in the FocNL. Performance and extensive comparison of these two model versions between each other and with observational estimates are described in $[10-12,15,17]$. There, it is shown that both versions behave realistically in the 20th century and their projections for the 21st century are basically in line with those obtained in the $\mathrm{C}^{4} \mathrm{MIP}$ project. The simulations performed here were forced by idealised emission scenarios. In these scenarios, fossil fuel emissions increase exponentially in time with a time scale $t_{p}$ from $25 \mathrm{yr}$ to $250 \mathrm{yr}$ starting from the small initial value $E_{0}$ $=0.1 \mathrm{PgC} / \mathrm{yr}$. These emissions are not meant to represent any historical or future projected emissions. However, one notes that the combined fossil fuel emissions taken as historical for the 19-20th centiries [20] and adopted from the Special Report on Emission Scenarios [21] for the 21st century (except the scenario B1 where fossil fuel emissions decline in the late 21st century) may be approximated by an exponential curve with $t_{p}$ changing from 50 $y r$ to $200 y r$ depending on scenario. One notes that an emission intensity depends both on $E_{0}$ and $t_{p}$. Thus, strictly speaking, quantitative results presented below are only valid for this particular choice of $E_{0}$. However, qualitative conclusions are unlikely to be changed if other sufficiently small value of $E_{0}$ is selected. In some sense, larger $t_{p}$ may be partly compensated by larger $E_{0}$. In the performed simulations, land use emissions are neglected. Every simulation starts from the model's preindustrial equilibrated state and proceeds for 1,500 $\mathrm{yr}$.

As shown in Fig. 1, climate-carbon cycle feedback parameter attains maximum and than eventualy falls down tending to unity. This behaviour is in general agreement with those obtained in the earlier IAP RAS CM simulations $[11,15]$ and employing a conceptual climate-carbon cycle model [16]. There is a difference in timing $t_{m}$ when $f$ is at maximum between the two employed here IAP RAS $\mathrm{CM}$ versions. For the studied here range of $t_{p^{\prime}} t_{m}$ ranges from $3 \times t_{p}$ to $5 \times t_{p}$ in simulations with the FocL and from $5 \times t_{p}$ to $8 \times t_{p}$ in simulations with the FocNL. For both model versions, the larger $t_{p}$ the earlier (in units of $t_{p}$ ) this maximum of $f$ occurs. Difference in responses of the globally and annually averaged surface air temperatures between coupled and uncoupled simulation also increases early in the simulations, then attains a maximum (which occurs later than $t_{m}$ ) and diminishes afterwards tending to zero (not shown). To diagnose the behavior of the model, an approach by [5] has been 
adopted. In this, coefficients $\gamma_{X}$ and $\beta_{X}(X=l, o c)$ entering (2) were computed for the running 100-yr segments. For both model versions, $\beta_{l}$ increases till the plants fertilisation half-saturation point is reached and then decreases to zero (see Fig. 2a as an example). This behaviour reflects the Michaelis-Menten-type dependence of terrestrial productivity on $q_{\mathrm{CO}_{2}}$ as it is implemented in the IAP RAS CM. Coefficient $\beta_{o c}$ behaves similarly in the version FocNL while changes in time only slightly in the version FocL. This is expected from the formulations of $F_{o c}$ in these model versions. In contrast, the magnitudes of $\gamma_{l}$ and $\gamma_{o c}$ increse during the course of integration (Fig. 2b).

This behaviour of $\beta$ s and $\gamma$ s obviously leads to the magnitude of $G$ (see (2)) increasing with time if the latter is large enough (perticularly, after $t_{m^{\prime}}$ not shown). Consequently, general decrease of gain $g$ and feedback parameter $f$ is due to drastic decrease of transient temperature sensitivity $\alpha$ in the course of integration. Being computed for 100-yr running segments, $\alpha$ shows almost monotonic decrease during the course of integration by an order of magnitude (Fig. 3). This decrease overcompensates an increase of $G$ with time. Such a decrease of sensitivity is again consistent with a commonly accepted weak, logarithmic dependence of the carbon dioxide instantaneous radiative forcing on the $\mathrm{CO}_{2}$ atmospheric content. To get an impression, how

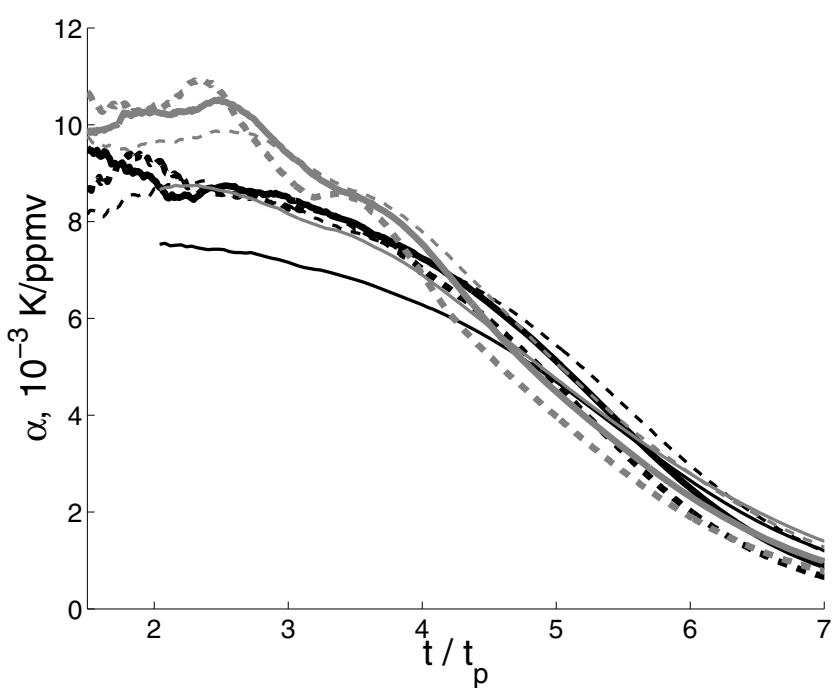

Figure 3

Transient temperature sensitivity a computed for 100 -year running segments from the simulations with the IAP RAS CM versions FocL and FocNL with different $t_{p}$. Notations are the same as in Fig. I. large $q_{\mathrm{CO}_{2}}$ should be for eventual transient saturation, the time when $f$ eventually becomes smaller than 1.05 is computed and the corresponding value $q_{\mathrm{CO}_{2}, \mathrm{~s}}$ is stored. This value ranges between $3226 p p m v$ and $6152 p p m v$ (3679 ppmv and $12799 p p m v$ ) for the version FocL (FocNL). The smaller values in these ranges correspond to the larger values of $t_{p}$. While the upper part of these ranges seems unrealistic (especially that obtained for the version FocNL), the lower part can be achieved if future $\mathrm{CO}_{2} \mathrm{emis}$ sion come along the worst (e.g., SRES A2) path. It is important with this respect that this lower part of range is obtained for $t_{p}=150-250 y r$ which is applicable for the SRES scenarios.

\section{Analysis of a conceptual model}

In this section, a conceptual coupled model similar, but not identical to [16] is employed. An important distinction between the present paper and [16] is as follows. In [16], a build up of carbon dioxide in the atmosphere in the uncoupled simulation is prescribed. In contrast, in the present paper, the model is forced by idealised emission scenarios. This results in different time scales used in these two papers. Here, $t_{p}$ means time scale of emission growth while in the earlier paper the time scale for $q_{\mathrm{CO}_{2}}^{u c p l}$ growth was used. The latter approach implicitly includes all details of emissions and direct fertilisation via prescribed curve $q_{\mathrm{CO}_{2}}^{u c p l}(t)$. However, the time scale associated with $q_{\mathrm{CO}_{2}}^{u c p l}(t)$ is larger than $t_{p}$ by an order of magnitude. As a result, to be consistent with the above analysis of the IAP RAS CM, an emission time scale is used here. The equations for the airborne carbon storage for the coupled and uncoupled cases are, respectively,

$$
\begin{gathered}
c_{0} d q_{\mathrm{CO}_{2}}^{c p l} / d t=E-F_{o c}^{c p l}-F_{l}^{c p l}, \\
c_{0} d q_{\mathrm{CO}_{2}}^{u c p l} / d t=E-F_{o c}^{u c p l}-F_{l}^{u c p l},
\end{gathered}
$$

where $c_{0}=2.1 \mathrm{PgC} / \mathrm{ppm} v, E$ stands for emissions, and $F_{l}$ and $F_{o c}$ are terrestrial and oceanic carbon uptakes, respectively. Linearising carbon fluxes [5] and neglecting difference between the changes of globally averaged annual mean surface air and sea surface temperatures one obtains

$$
\begin{aligned}
& F_{X}^{c p l}=\beta_{X} d q_{\mathrm{CO}_{2}}^{c p l} / d t+\gamma_{X} d T_{g}^{c p l} / d t, \\
& F_{X}^{u c p l}=\beta_{X} d q_{\mathrm{CO}_{2}}^{u c p l} / d t,
\end{aligned}
$$


where $X=l, o c, T_{g}$ stands for globally averaged annual mean temperature, and $\gamma_{X}$ and $\beta_{X}$ were defined in Introduction. From (3)-(5) one derives

$$
\Delta q_{\mathrm{CO}_{2}}^{c p l}=\Delta q_{\mathrm{CO}_{2}}^{u c p l}+\kappa \Delta T_{g}^{c p l}
$$

with $\kappa=-G=\left(\gamma_{l}+\gamma_{o c}\right) /\left(c_{0}+\beta_{l}+\beta_{o c}\right)$, see Eq. (2). For the $\mathrm{C}^{4} \mathrm{MIP}$ models under the emission scenario SRES A2, from [14] one derives $\kappa=(8-48) p p m v / K$ for the 21st century. Coefficient $\beta=\beta_{l}+\beta_{o c}$ varies from $1.7 \mathrm{PgC} / \mathrm{ppm} v$ to 3.7 $\mathrm{PgC} / \mathrm{ppm} v$ with a mean value $2.5 \mathrm{PgC} / \mathrm{ppm} v$ [14]. For the the IAP RAS CM ensemble simulation, $\kappa$ depends on $t_{p}$. Here, at a time short before $t_{m}, \kappa$ varies from very small values for $t_{p}=25 \gamma r$ up to $25 p p m v / K(35 p p m v / K)$ for the version FocNL (FocL) if $t_{p}=250 y r$. Coefficient $\beta$ depends on $t_{p}$ as well. At time of a few $t_{p}$, it again attains very small values for $t_{p}=25 \mathrm{yr}$ and amounts $1.6 \mathrm{PgC} / \mathrm{ppm} v(2.5 \mathrm{PgC} /$ $p p m v$ ) for the version FocL (FocNL) for $t_{p}=250 y r$.

For the same exponentially growing emissions as those used to force the IAP RAS CM in the previos Subsection, and for the uncoupled case, Eq. 4 may be integrated analytically to give

$$
q_{\mathrm{CO}_{2}}^{u c p l}=q_{\mathrm{CO}_{2}, 0}+\frac{E_{0} t_{p}}{c_{0}+\beta}\left(\exp \left(t / t_{p}\right)-1\right)
$$

with the initial atmospheric carbon dioxide concentration $\mathrm{C}_{0}$.

For coupled simulation, one may write [22]

$$
F_{H}^{c p l}=R^{c p l}-\lambda \Delta T_{g}^{c p l}
$$

where $F_{H}^{c p l}$ is oceanic heat uptake, $R^{c p l i s}$ radiative forcing. The latter is substituted as $R^{c p l}=R_{0} \ln \left(q_{\mathrm{CO}_{2}}^{c p l} / q_{\mathrm{CO}_{2}, 0}\right)$ with $R_{0}=5.4 \mathrm{Wm}^{-2} \mathrm{~K}^{-1}[21,23]$. Climate feedback parameter is $\lambda=R_{0} \ln 2 / \Delta T_{2 \times \mathrm{CO}_{2}}$ with $\Delta T_{2 \times \mathrm{CO}_{2}}$ standing for the equilibrium model sensitivity to doubling of the atmospheric carbon dioxide concentartion. Upon substituting $F_{H}^{c p l}=C d \Delta T_{g}^{c p l} d t \quad(C$ is heat capacity per unit area) one gets

$$
C=\frac{d \Delta T_{g}^{c p l}}{d t}=R_{0} \ln \left(1+\frac{\Delta q_{C O_{2}}^{c p l}}{q C O_{2}, 0}\right)-\lambda \Delta T_{g}^{c p l}
$$

Alternatively, Eq. (9) may be treated as a simple zerodimensional climate model [24].
Eqs. (6), (7) and (9) have been numerically integrated subject to the above-mentioned exponential emissions (expressed via (7)) and to initial condition $\left.\Delta T_{g}^{c p l}\right|_{t=0}=0$. An ensemble of conceptual model integrations is performed varying $t_{p}$ in the same range as it was for IAP RAS $\mathrm{CM}$ and varying $\beta$ in the range from 0 to $5.0 \mathrm{PgC} / \mathrm{ppm} v$ (this range is wider than the corresponding $\mathrm{C}^{4} \mathrm{MIP}$ range, see above). Equilibrium model sensitivity to doubling of the carbon dioxide in the atmosphere was varied between $1 \mathrm{~K}$ and $9 \mathrm{~K}$ roughly corresponding to combined range from [25-28] (in [29], a narrower range from $2.0 K$ to 4.5 $K$ is figured). Parameter $\kappa$ was varied from $8 p p m v / K$ to 48 $p p m v / K$ (see above).

In all these integrations, $f$ attains maximum and then falls down to unity (Fig. 4a). The timing of this maximum is $t_{m}$ $=(2-8) \times t_{p}$ depending on governing parameters. The lat ter range is similar to that obtained in the simulations with the IAP RAS CM despite of the fixed value of $\Delta T_{2 \times \mathrm{CO}_{2}}$ of smaller range of variations in $\beta$ in the IAP RAS $\mathrm{CM}$. In particular, the latter parameter was varied only between two values, one corresponding to the version FocL and the other corresponding to the version FocNL. Moreover, if a narrower range of $\Delta T_{2 \times \mathrm{CO}_{2}}$ figured in [29] is considered and/or $\beta$ is constrained to be in a $\mathrm{C}^{4} \mathrm{MIP}$ range, an interval for $t_{m} / t_{p}$ shrinks only slightly in the integrations with a conceptual model. The obtained $t_{m} / t_{p}$ is insensitive to variations in $\kappa$ This is consistent with the results obtained in [16]. Typically, $t_{m} / t_{p}$ increases if any of $\Delta T_{2 \times \mathrm{CO}_{2}}$ and $\beta$ increases or $t_{p}$ decreases (see Fig. $4 \mathrm{a}$ ). For variations in $t_{p}$, this behaviour is consistent with that obtained employing the IAP RAS CM. For variations in $\beta$, it is consistent as well since combined $\beta$ for the version FocL is larger than for the version FocNL (basically, due to larger $\beta_{o c}$ for the former model version, see [15]).

In a conceptual model, by construction, $G=-\kappa$ does not change during the course of integration. As a result, as it was for the IAP RAS CM, eventual tending of $f$ to unity is due to decrease in transient temperature sensitivity $a$ during the course of integration (Fig. 4b). In turn, this is due to weak, logarithmic dependence of the $\mathrm{CO}_{2}$ radiative forcing on the atmospheric concentration of carbon dioxide. One may estimate $q_{\mathrm{CO}_{2,} \text {, from this conceptual model }}$ as well. For simplicity, one may assume that temperature 
a)

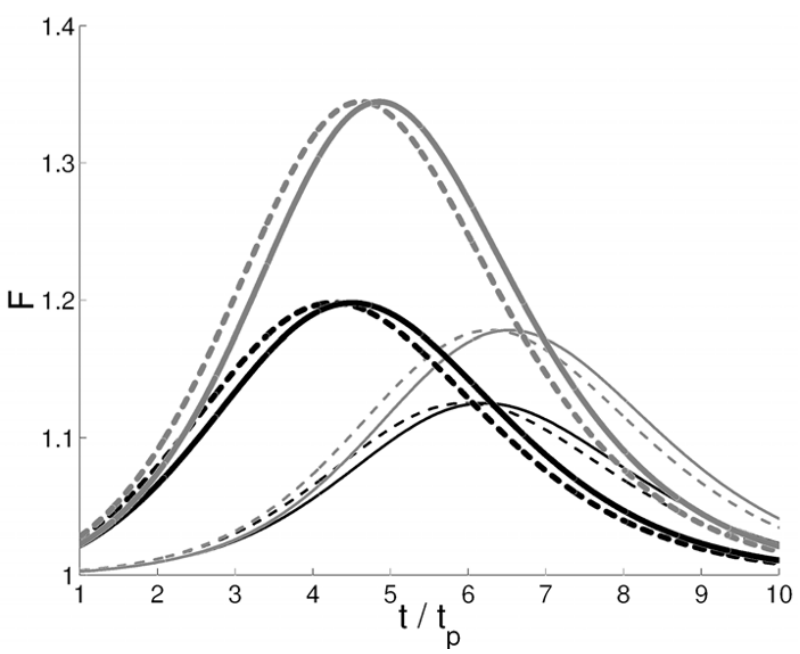

b)

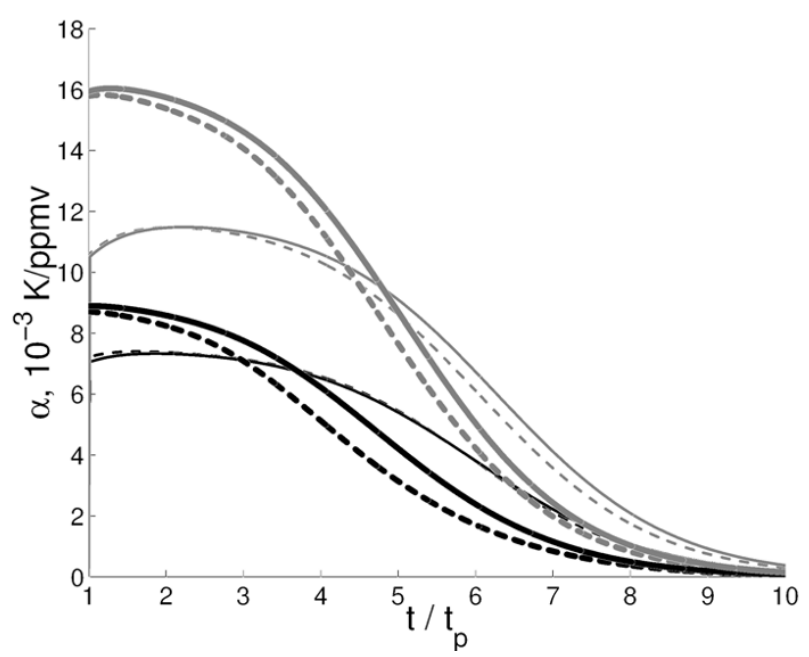

Figure 4

Parameter of climate-carbon cycle interaction in the conceptual model (a) and transient temperature sensitivity $\alpha$ computed for 100 -year running segments (b) as functions of $t / t_{p}$. Shown are curves for $t_{p}=50$ and I $50 \mathrm{yr}$ (thin and thick lines respectively) with $\beta=1.5$ and 2.5 PgClppmv (dashed and solid lines correspondingly) and $\Delta T_{2 \times \mathrm{CO}_{2}}=2$ and $4 \mathrm{~K}$ (black and gray lines respectively) for $\kappa$ $=28 \mathrm{ppmv} / \mathrm{K}$.

response to carbon dioxide forcing is stationary. This is achieved by dropping $F_{H}^{c p l}$ in Eq. (8). Taking into accout Eq. (6), one obtains

$$
\frac{\kappa \Delta T_{2 \times \mathrm{CO}_{2}}}{q \mathrm{CO}_{2, s} \ln 2} \ln \frac{q \mathrm{CO}_{2, s}}{q \mathrm{CO}_{2}, 0}=0.05
$$

where again the threshold value for $f$ is set to 1.05 . This equation has been solved numerically appling the dichotomy method. In general, the larger $\kappa$ and/or $\Delta T_{2 \times \mathrm{CO}_{2}}$ the larger $q_{\mathrm{CO}_{2}, s}$. For $\Delta T_{2 \times \mathrm{CO}_{2}}=2.2 \mathrm{~K}$, the values obtained for the conceptual model are similar, but slightly larger, to those estimated from the IAP RAS CM runs.

As an aside issue, one may quantify how "small" $E_{0}$ should be in order not to make the approach followed here meaningless. Physically, $E_{0}$ has not to result in sudden kink in $q_{\mathrm{CO}_{2}}^{u c p l}$ at $t=0$. From Eq. (7), it needs

$$
E_{0} \ll\left(c_{0}+\beta\right) q_{\mathrm{CO}_{2}, 0} / t_{p} \leq c_{0} q_{\mathrm{CO}_{2}, 0} / t_{p} \leq 2.4 \mathrm{PgC} / \mathrm{\gamma r} .
$$

The value of $E_{0}$ selected in this paper, $0.1 \mathrm{PgC} / \mathrm{yr}$, fulfills this condition. If (11) is satisfied then qualitative conclusion of the present paper and the respective conclusions related to the order of magnitudes of basic characteristics are expected to remain unchanged.

\section{Discussion}

An eventual transient saturation, as studied in the present framework, implies that initially (at a time $<t_{p}$ ) and eventually (at a time $\gg t_{p}$ ), the state of the coupled system is close to the state of the uncoupled one. However, during an intermediate period when $t^{\prime} \simeq t_{p^{\prime}} f$ deviates substantinally from unity and climate-carbon cycle interaction does matter. Taking into account typical time scales of $\mathrm{CO}_{2}$ emission growth for the SRES emission, $t_{p}=50-200$ $y r$, this intermediate period extends for the next several centuries.

While it is beyond the scope of the present paper to concern $\mathrm{CO}_{2}$ emissions changing non-exponentially in time, it is possible to make a note with this respect. In particular, if the future emissions would change in time slower than the exponential ones, it would be expressed in apparent increase of $t_{p}$ during the course of simulation. In turn, the timing $t_{m}$ of maximum of $f$ and an eventual transient saturation would be delayed in comparison to the case with constant $t_{p}$. On the other hand, for faster-than-exponential emissions this eventual transient saturation would come closer to the present day.

The long-term fate of anthropogenic carbon is basically governed by calcium carbonate dissolution in the ocean $[30,31]$. This effect is taken into account only in the ver- 
sion FocNL and neglected in the version FocL and in the conceptual model. However, carbonate dissolution is important only for time scales larger than $\approx 5,000 \mathrm{yr}$ [30] which is well above the length of every individual simulation performed in the present paper $(1,500 y r)$. As a result, the version FocL and the conceptual climate-carbon cycle model are applicable for the problem considered here as well.

Returning to $\mathrm{C}^{4} \mathrm{MIP}$ simulations, one notes that it is possible to find some hints for this eventual transient saturation in these simulations [14] as well (see Background). However, in the $\mathrm{C}^{4} \mathrm{MIP}$ integrations, an eventual climatecarbon cycle carbon saturation is less marked. The most probable reason for this is the length of the $\mathrm{C}^{4} \mathrm{MIP}$ simulations which is too small to make this saturation visible given an emission intensity in these simulations. One expects that if these simulations would extended to the future, eventually, parameter $f$ would converge to unity in the $\mathrm{C}^{4} \mathrm{MIP}$ ensemble as well. Some complications for this convergence could arise from a specific behaviour of $a$ for particular models, e.g., due to behaviour of the oceanic heat uptake in the course of integration and its interrelation with equilibrium temperature sensitivity [32-35].

As a final note, one may distinguish manifestation of a climate-carbon cycle feedback eventual transient saturation in terms of feedback parameter, on one hand, and in terms of feedback gain, on the other one. In particular, as $d g / d t=f^{2} d f / d t$ and, generally, $f>1$ in the course of simulations, this saturation is somewhat masked for $g$ in comparison to $f$. This also adds to the masking of the eventual transient saturation of the climate-carbon cycle feedback in the $\mathrm{C}^{4} \mathrm{MIP}$ simulations.

\section{Conclusion}

In this paper, simulations with the IAP RAS climate model of intermediate complexity have been performed to study temporal variations of the climate-carbon cycle feedback parameter. Two model versions were considered differing between each other by the formulation of the oceanic uptake of carbon dioxide and by the governing parameters of the terrestrial carbon uptake module. Both versions were forced by idealised scenarios of fossil fuel emissions. In these scenarios, emissions grow exponentially in time (with a characteristic timescale $t_{p}=25-250 y r$ ) starting from a small initial emission value. Land use emissions were set to zero. In all simulations with both model versions, climate-carbon cycle feedback parameter $f$ grows initially, attains maximum, and then decreases eventually tending to unity. The timing of this maximum is of the order of a few $t_{p}$ for the selected small value of initial emission. This general behaviour is consistent to that obtained in a earlier simulations with the same model.
In particular, coefficients of climate-carbon cycle interaction diagnosed for 100-yr running segments lead to increase of climate-carbon cycle gain $g$ during the course of integration. This increase, however, is overcompensated by decrease of transient climate sensitivity $\alpha$. The latter leads to the above-mentioned eventual transient saturation of climate-carbon cycle feedback.

The IAP RAS CM simulations are supported by an analysis of a conceptual model with linear dependence of carbon sinks from the atmosphere on changes in atmospheric carbon dioxide concentration and global temperature rise. This simple model exhibits an eventual transient saturation of the climate-carbon cycle feedback which is similar to the model of intermediate complexity.

\section{Competing interests}

The authors declare that they have no competing interests.

\section{Authors' contributions}

Both authors equally contributed to the paper.

\section{Acknowledgements}

The authors are indebted to L.L. Golubyatnikov and A.M. Tarko for useful discussions on the topic of the manuscript. Comments by anonymous reviewers has led to improved presentation of the results. This work has been supported by the Russian Foundation for Basic Research (grants 05 05-64907, 05-05-65167, and 07-05-00273), the President of Russia grant 4166.2005 .5 , and by the Programs of the Russian Ministry for Science and Education, Russian Federal Agency for Science and Innovations and the Russian Academy of Sciences (contracts 02.5I 5. I I.503 I and 02.5 I5. I I.5046).

\section{References}

I. Cox P, Betts R, Jones C, Spall S, Totterdell I: Acceleration of global warming due to carbon-cycle feedbacks in a coupled climate model. Nature 2000, 408: |84- 187.

2. Friedlingstein P, Bopp L, Ciais P, Dufresne JL, Fairhead L, Le Treut H, Monfray $P$, Orr J: Positive feedback between future climate change and the carbon cycle. Geophys Res Lett 200I, 28(8): I 543-1546.

3. Brovkin V, Bendtsen J, Claussen M, Ganopolski A, Kubatzki C, Petoukhov V, Andreev A: Carbon cycle, vegetation, and climate dynamics in the Holocene: Experiments with the CLIMBER2 model. Glob Biogeochem Cycles 2002, I 6(4): I I 39.

4. Brovkin V, Sitch S, von Bloh W, Claussen M, Bauer E, Cramer W: Role of land cover changes for atmospheric $\mathrm{CO}_{2}$ increase and climate change during the last $\mathbf{I} 50$ years. Glob Change Biol 2004, 10:1253-1266.

5. Friedlingstein P, Dufresne JL, Cox P, Rayner P: How positive is the feedback between climate change and the carbon cycle? Tellus 2003, 55B(2):692-700.

6. Jones C, Cox P, Essery R, Roberts D, Woodage M: Strong carbon cycle feedbacks in a climate model with interactive $\mathbf{C O}_{2}$ and sulphate aerosols. Geophys Res Lett 2003, 30(9): I479.

7. Matthews H, Weaver A, Meissner K, Gillett N, Eby M: Natural and anthropogenic climate change: incorporating historical land cover change, vegetation dynamics and the global carbon cycle. Clim Dyn 2004, 22:46 I-479.

8. Matthews H, Weaver A, Meissner K: Terrestrial carbon cycle dynamics under recent and future climate change. I Climate 2005, 18(10): 1609-1628.

9. Govindasamy B, Thompson S, Mirin A, Wickett M, Caldeira K, Delire $\mathrm{C}$ : Increase of carbon cycle feedback with climate sensitivity: results from a coupled climate and carbon cycle model. Tellus 2005, 57B(2): I 53-I 63. 
10. Mokhov I, Eliseev A, Karpenko A: Sensitivity of the IAP RAS Global Climatic Model with an interactive carbon cycle to anthropogenic influence. Doklady Earth Sci 2006, 407(3):424-428.

II. Eliseev A, Mokhov I, Karpenko A: Climate and carbon cycle variations in the 20th and 21 st centuries in a model ofintermediate complexity. Izvestiya, Atmos Ocean Phys 2007, 43:I-I4.

12. Eliseev A, Mokhov I: Carbon cycle-climate feedback sensitivity to parameter changes of a zero-dimensional terrestrial carbon cycle scheme in a climate model of intermediate complexity. Theor Appl Climatol 2007, 89(I-2):9-24.

13. Bala G, Caldeira K, Mirin A, Wickett M, Delire C: Multicentury changes to the global climate and carbon cycle: Results from a coupled climate and carbon cycle model. J Climate 2005, I 8(2I):453I-4544.

14. Friedlingstein $\mathrm{P}$, Cox $\mathrm{P}$, Betts R, Bopp L, von Bloh W, Brovkin V, Doney S, Eby M, Fung I, Govindasamy B, John J, Jones C, Joos F, Kato T, Kawamiya M, Knorr W, Lindsay K, Matthews H, Raddatz T, Rayner P, Reick C, Roeckner E, Schnitzler KG, Schnur R, Strassmann K, Weaver A, Yoshikawa C, Zeng N: Climate-carbon cycle feedback analysis: Results from the C4MIP model intercomparison. J Climate 2006, 19(22):3337-3353.

15. Mokhov I, Eliseev A, Karpenko A: Decadal-to-centennial scale climate-carbon cycle interactions from global climate models simulations forced by anthropogenic emissions. In Climate Change Research Progress Edited by: Peretz L. Hauppauge, NY: Nova Publishers; 2008 in press.

16. Eliseev A, Mokhov I: Eventual saturation of the climate-carbon cycle feedback studied with a conceptual model. Ecol Mod 2008, 21 3:127-132.

17. Mokhov I, Eliseev A, Demchenko P, Khon V, Akperov M, Arzhanov M, Karpenko A, Tikhonov V, Chernokulsky A, Sigaeva E: Climate changes and their assessment based on the IAP RAS global model simulations. Doklady Earth Sci 2005, 402(4):59I-595.

18. Bacastow R: Numerical evaluation of the evasion factor. In Carbon Cycle Modelling, SCOPE-I 6 Edited by: Bolin B. N.Y.: J. Wiley and Sons; 1981:95-101.

19. Millero F: Thermodynamics of carbon dioxide system in the ocean. Geophys Cosmophys Acta 1995, 59(4):661-677.

20. Marland G, Boden T, Andres R: Global, regional, and national CO2 emissions. In Trends: A Compendium of Data on Global Change Oak Ridge, Tenn.: Carbon Dioxide Information Analysis Center, Oak Ridge National Laboratory, U.S. Department of Energy; 2005.

21. Houghton J, Ding Y, Griggs D, Noguer M, Linden P van der, Dai $X$, Maskell K, Johnson C, (Eds): Climate Change 200I: The Scientific Basis. Contribution of Working Group I to the Third Assessment Report of the Intergovernmental Panel on Climate Change Cambridge/New York: Cambridge University Press; 2001.

22. Gregory J, Stouffer R, Raper S, Stott P, Rayner N: An observationally based estimate of the climate sensitivity. J Climate 2002, I5(22):3||7-3|2|.

23. Myhre G, Highwood E, Shine K, Stordal F: New estimates of radiative forcing due to well mixed greenhouse gases. Geophys Res Lett 1998, 25(14):2715-2718.

24. Andreae M, Jones C, Cox P: Strong present-day aerosol cooling implies a hot future. Nature 2005, 435: I I87-I I90.

25. Harvey L, Kaufmann R: Simultaneously constraining climate sensitivity and aerosol radiative forcing. J Climate 2002, I 5(20):2837-286I.

26. Stainforth D, Aina T, Christensen C, Collins M, Faull N, Frame D, Kettleborough J, Knight S, Martin A, Murphy J, Piani C, Sexton D, Smith L, Spicer R, Thorpe A, Allen M: Uncertainty in predictions of the climate response to rising levels of greenhouse gases. Nature 2005, 433:403-406.

27. Forest $C$, Stone $P$, Sokolov A: Estimated PDFs of climate system properties including natural and anthropogenic forcings. Geophys Res Lett 2006, 33:L0I705.

28. Hegerl G, Crowley T, Hyde W, DJ F: Climate sensitivity constrained by temperature reconstructions over the past seven centuries. Nature 2006, 440:1029-1032

29. Solomon S, Qin D, Manning M, Marquis M, Averyt K, Tignor M, LeRoy Miller H, Chen Z, (Eds): Climate Change 2007: The Physical Science Basis Cambridge/New York: Cambridge University Press; 2007.

30. Archer D, Martin P, Buffett B, Brovkin V, Rahmstorf S, Ganopolski A: The importance of ocean temperature to global biogeochemistry. Earth Planet Sci Lett 2004, 222(2):333-348.
31. Scheffer M, Brovkin V, Cox P: Positive feedback between global warming and atmospheric $\mathrm{CO}_{2}$ concentration inferred from past climate change. Geophys Res Lett 2006, 33(10):LI0702.

32. Hansen J, Russell G, Lacis A, Fung I, Rind D, Stone P: Climate response times: dependence on climate sensitivity and ocean mixing. Science 1985, 229(47|6):857-859.

33. Harvey L: Effect of ocean mixing on the transient climate response to $\mathrm{COO}_{2}$ increase: analysis of recent model results. J Geophys Res 1986, 90:2709-27।8.

34. Schlesinger $M$, Jiang $X$ : Simple model representation of atmosphere-ocean GCMs and estimation of the time scale of $\mathrm{CO}_{2}$ induced climate change. I Climate 1990, 3(12):1297-1315.

35. Raper S, Gregory J, Stouffer R: The role of climate sensitivity and ocean heat uptake on AOGCM transient temperature and thermal expansion response. J Climate 2002, I5:124-130.
Publish with Biomed Central and every scientist can read your work free of charge

"BioMed Central will be the most significant development for disseminating the results of biomedical research in our lifetime. "

Sir Paul Nurse, Cancer Research UK

Your research papers will be:

- available free of charge to the entire biomedical community

- peer reviewed and published immediately upon acceptance

- cited in PubMed and archived on PubMed Central

- yours - you keep the copyright 